DOI 10.26886/2520-7474.1(39)2020.5

UDC 378.14:378.22:631/635

\title{
RESULTS OF THE EXPERIMENTAL RESEARCH OF \\ AGRICULTURAL ENGINEERING BACHELOR'S READINESS FOR \\ PROFESSIONAL ACTIVITY IN THE CONDITIONS OF INFORMATION \\ AND EDUCATIONAL ENVIRONMENT
}

\section{N. Dotsenko, PhD, Associate Professor}

http//orcid.org/0000-0003-1050-8193

dotsenkona@outlook.com

Mykolayiv National Agrarian University, Mykolayiv, Ukraine

The article presents the results of an experimental research of agricultural engineering barchelor's readiness for professional activity in the conditions of informational and educational environment. It is described the procedure of experimental work. The reliability of the obtained results was tested using the Kolmogorov-Smirnov statistical criterion at the end of the experiment in the experimental and control groups. to the molding stage upon completion of the molding experiment. It is presented the comparison of the level of readiness for professional activity in the conditions of information and educational environment in terms of research-creative, plan-motivational, constructive-operative and reflexive-evaluation criterion to the formation stage at the end of the forming experiment.

Key words: readiness for professional activity, bachelors in agricultural engineering, information and educational environment.

Кандидат технічних наук, доцент Доценко Н. А. Результати експериментального дослідження перевірки готовності бакалаврів з агроінженерії до професійної діяльності в умовах інформаційноосвітнього середовища. Миколаївський національний аграрний університет, м. Миколаїв, Україна. 
У статті представлено результати експериментального дослідження перевірки готовності бакалаврів з агроінженерії до профресійної діяльності в умовах інформаційно-освітнього середовища. Описана процедура проведення експериментальної роботи. Перевірено достовірність отриманих результатів за допомогою статистичного критерію Колмогорова-Смирнова по завершенню експерименту в експериментальних та контрольних групах Представлено співставлення рівня сфрормованості готовності до профресійної діяльності в умовах інформаційноосвітнього середовища за дослідницько-творчим, плановомотиваційним, конструктивно-операційним та рефрлексивнооцінювальним критерієм до формувального етапу по завершенню формувального експерименту.

Ключові слова: готовність до професійної діяльності, бакалаври з агроінженерії, інфрормаційно-освітнє середовище.

Вступ. Створення навчальних курсів в умовах інформаційноосвітнього середовища для навчання бакалаврів 3 агроінженерії $€$ новим, і недостатньо дослідженим методом навчання з використанням нових підходів. Система освіти в умовах інформаційно-освітнього середовища недостатньо пов'язана 3 навчальним процесом в університетах, які забезпечують підготовку фрахівців шляхом формування відповідних компетентностей. Але перспектива розвитку агроінженерної освіти в умовах інформаційно-освітнього середовища пов'язана з просуванням систем відкритої освіти. На додаток до традиційних матеріалів таких як відео й друковані матеріали, навчальні курси в умовах інформаційно-освітнього середовища надають інтерактивні можливості для здобувачів вищої освіти агроінженерних спеціальностей. Для підготовки бакалаврів з агроінженерії в умовах 
інформаційно-освітнього середовища пропонується використовувати такі інструменти як лекції 3 аудіовізуальним супроводом, вебінари, онлайн-глосарій, проблемні семінари, інтерактивні мультимедійні лекції, круглі столи в рамках тематичних фрорумів, онлайн практичні заняття, інтерактивні завдання, навчальні комп'ютерні інтерактивні тренажери, відео конференції, наукові проекти із використанням елементів STEM-освіти тощо.

Виклад основного матеріалу. Дослідження готовності бакалаврів з агроінженерії до профресійної діяльності в умовах інформаційноосвітнього середовища потребує експериментальної перевірки запропонованої моделі.

Процедура проведення експериментальної роботи включала такі послідовні дії:

- відбір контрольних і експериментальних груп (однорідних);

- розробку методичного інструментарію для оцінки за критеріями і показниками наявного рівня сформованості знань, умінь, навичок бакалаврів 3 агроінженерії, що відображають рівень готовності здобувача вищої освіти спеціальності «Агроінженерія» до професійної діяльності;

- визначення й констатація рівня ссрормованості готовності бакалаврів 3 агроінженерії до професійної діяльності в умовах інформаційно-освітнього середовища;

- впровадження авторської моделі, технології професійної підготовки майбутніх агроінженерів в умовах інфрормаційно-освітнього середовища;

- порівняння показників рівня сформованості готовності бакалаврів 3 агроінженерії до профресійної діяльності після впровадження авторських розробок; 
- кількісний та якісний аналіз динаміки розвитку рівня сформованості готовності бакалаврів з агроінженерії до професійної діяльності;

- узагальнення й висновок про ефективність та результативність запропонованих авторських розробок, які характеризуються взаємозв'язком залежних та незалежних змінних (методів, засобів навчання і результатів у фіксованих умовах та ін.).

Мета та завдання дослідження зумовили завдання педагогічного експерименту - через практичне упровадження обґрунтувати ефективність та результативність розробленої моделі підготовки бакалаврів 3 агроінженерії до професійної діяльності в умовах інформаційно-освітнього середовища.

Перевіримо достовірність отриманих результатів за допомогою статистичного критерію Колмогорова-Смирнова по завершенню експерименту в експериментальних та контрольних групах. Сфрормуємо статистичні гіпотези для перевірки рівня готовності бакалаврів з агроінженерії до професійної діяльності в умовах інфрормаційно-освітнього середовища за планово-мотиваційним критерієм. $\mathrm{H}_{0}$ : кількість бакалаврів 3 агроінженерії, у яких рівень готовності до професійної діяльності в умовах інформаційно-освітнього середовища за планово-мотиваційним критерієм до фрормувального етапу в експериментальній групі не вищий, ніж у контрольній. $\mathrm{H}_{1}$ : кількість бакалаврів з агроінженерії, у яких рівень готовності до професійної діяльності в умовах інформаційно-освітнього середовища за планово-мотиваційним критерієм до формувального етапу в експериментальній групі вищий, ніж у контрольній.

Представимо графрічне розташування емпіричного значення у зоні значущості 3 урахуванням критичного для співставлення рівня сфрормованості готовності до професійної діяльності в умовах інфрормаційно-освітнього середовища за планово-мотиваційним 
критерієм по завершенню фрормувального етапу по завершенню формувального експерименту (рис.1).

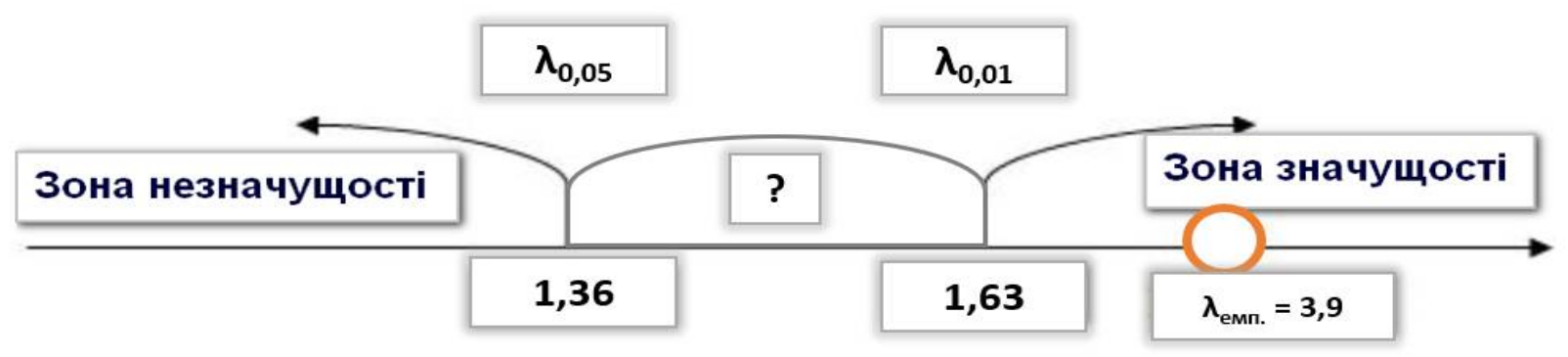

Рис. 1. Графрічне розташування емпіричного значення у зоні значущості з урахуванням критичного для співставлення рівня сформованості готовності до професійної діяльності в умовах інформаційно-освітнього середовища за планово-мотиваційним критерієм до формувального етапу по завершенню формувального експерименту

Так, $\lambda_{\text {емп. }}<\lambda_{\text {контр }} \mathrm{H}_{0}-$ відхиляється, зберігається гіпотеза $\mathrm{H}_{1}$. Кількість бакалаврів з агроінженерії, у яких рівень готовності до професійної діяльності в умовах інформаційно-освітнього середовища за планово-мотиваційним критерієм до формувального етапу в експериментальній групі вищий, ніж у контрольній.

Сформуємо статистичні гіпотези для перевірки рівня готовності бакалаврів 3 агроінженерії до професійної діяльності в умовах інформаційно-освітнього середовища за конструктивно-операційним критерієм. Но: кількість бакалаврів з агроінженерії, у яких рівень готовності до професійної діяльності в умовах інформаційно-освітнього середовища за конструктивно-операційним критерієм до фрормувального етапу в експериментальній групі не вищий, ніж у контрольній. $\mathrm{H}_{1}$ : кількість бакалаврів з агроінженерії, у яких рівень готовності до професійної діяльності в умовах інформаційно-освітнього середовища за конструктивно-операційним критерієм до 
формувального етапу в експериментальній групі вищий, ніж у контрольній. Представимо графічне розташування емпіричного значення у зоні значущості 3 урахуванням критичного для співставлення рівня сорормованості готовності до професійної діяльності в умовах інформаційно-освітнього середовища за конструктивно-операційним критерієм до формувального етапу по завершенню формувального експерименту (Рис. ).

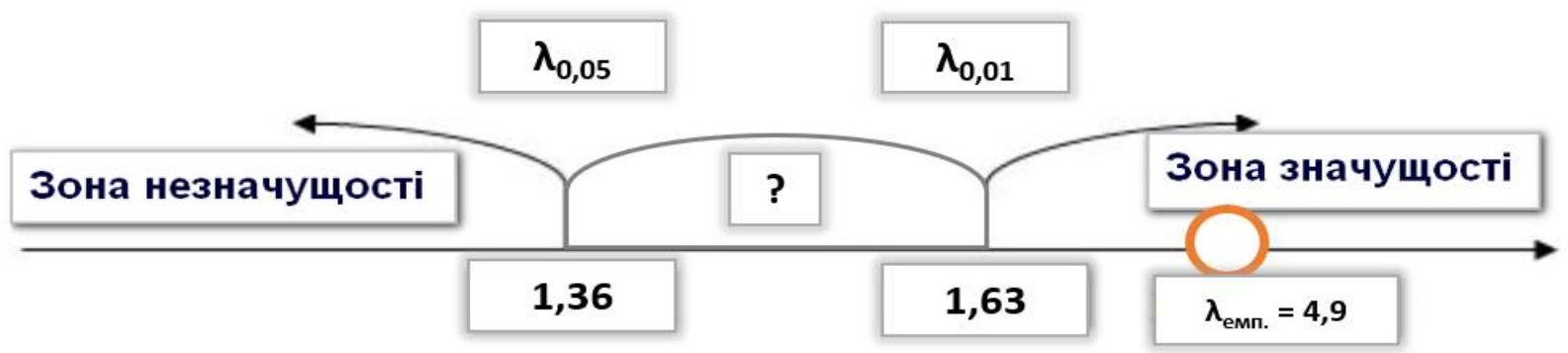

Рис. 2. Графрічне розташування емпіричного значення у зоні значущості з урахуванням критичного для співставлення рівня сформованості готовності до професійної діяльності в умовах інформаційно-освітнього середовища за конструктивноопераційним критерієм до формувального етапу по завершенню формувального експерименту

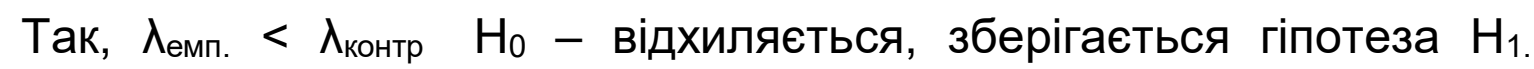
Кількість бакалаврів 3 агроінженерії, у яких рівень готовності до професійної діяльності в умовах інформаційно-освітнього середовища за конструктивно-операційним критерієм до формувального етапу в експериментальній групі вищий, ніж у контрольній.

Сформуємо статистичні гіпотези для перевірки рівня готовності бакалаврів 3 агроінженерії до професійної діяльності в умовах інформаційно-освітнього середовища за рефлексивно-оцінювальним критерієм. Н0: кількість бакалаврів з агроінженерії, у яких рівень готовності до професійної діяльності в умовах інформаційно-освітнього середовища за рефлексивно-оцінювальним критерієм до формувального етапу в експериментальній групі не вищий, ніж у 
контрольній. $\mathrm{H}_{1}$ : кількість бакалаврів 3 агроінженерії, у яких рівень готовності до професійної діяльності в умовах інформаційно-освітнього середовища за рефлексивно-оцінювальним критерієм до фрормувального етапу в експериментальній групі вищий, ніж у контрольній.

Представимо графрічне розташування емпіричного значення у зоні значущості 3 урахуванням критичного для співставлення рівня сфрормованості готовності до професійної діяльності в умовах інформаційно-освітнього середовища за рефлексивно-оцінювальним критерієм до формувального етапу по завершенню формувального експерименту (Рис. ).

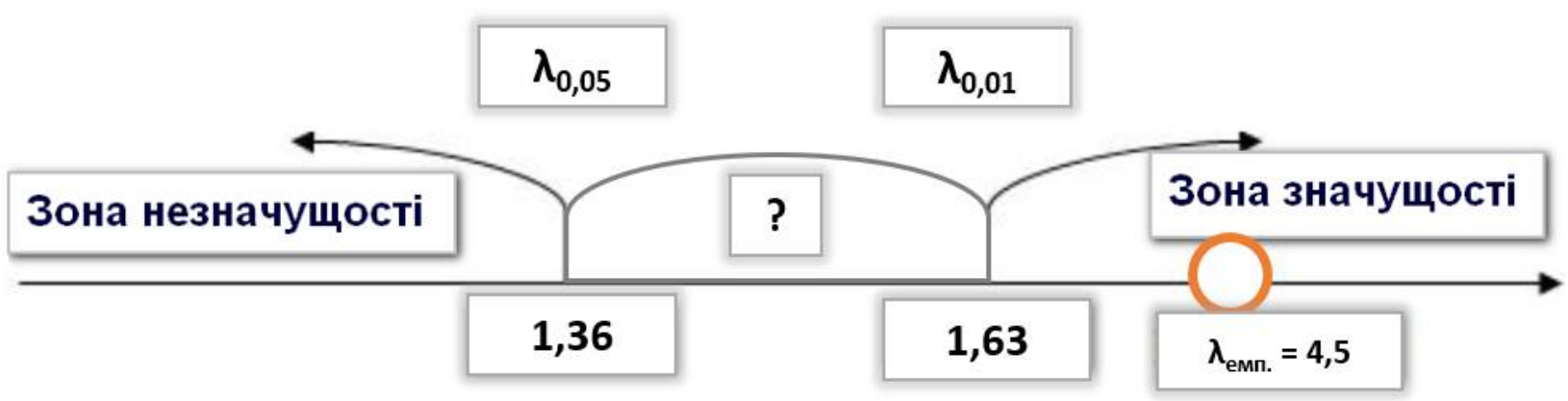

Рис. 3. Графрічне розташування емпіричного значення у зоні значущості 3 урахуванням критичного для співставлення рівня сформованості готовності до професійної діяльності в умовах інформаційно-освітнього середовища за рефлексивнооцінювальним критерієм до формувального етапу по завершенню формувального експерименту

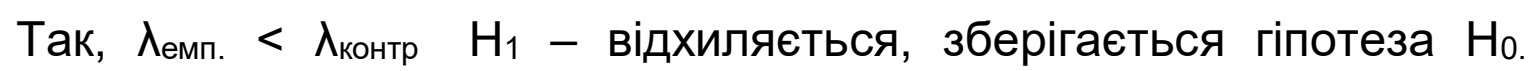
Кількість бакалаврів з агроінженерії, у яких рівень готовності до професійної діяльності в умовах інформаційно-освітнього середовища за рефлексивно-оцінювальним критерієм до формувального етапу в експериментальній групі не вищий, ніж у контрольній.

Сфрормуємо статистичні гіпотези для перевірки рівня готовності бакалаврів з агроінженерії до професійної діяльності в умовах 
інформаційно-освітнього середовища за дослідницько-творчим критерієм. Но: кількість бакалаврів з агроінженерії, у яких рівень готовності до професійної діяльності в умовах інформаційно-освітнього середовища за дослідницько-творчим критерієм до фрормувального етапу в експериментальній групі не вищий, ніж у контрольній. $\mathrm{H}_{1}$ : кількість бакалаврів з агроінженерії, у яких рівень готовності до професійної діяльності в умовах інформаційно-освітнього середовища за дослідницько-творчим критерієм до фрормувального етапу в експериментальній групі вищий, ніж у контрольній.

Представимо графрічне розташування емпіричного значення у зоні значущості 3 урахуванням критичного для співставлення рівня сфрормованості готовності до професійної діяльності в умовах інформаційно-освітнього середовища за дослідницько-творчим критерієм до формувального етапу по завершенню фрормувального експерименту (Рис. ).

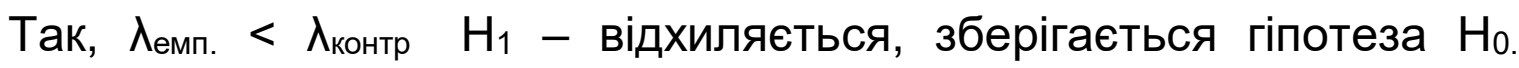
кількість бакалаврів з агроінженерії, у яких рівень готовності до професійної діяльності в умовах інформаційно-освітнього середовища за дослідницько-творчим критерієм до фрормувального етапу в експериментальній групі не вищий, ніж у контрольній.

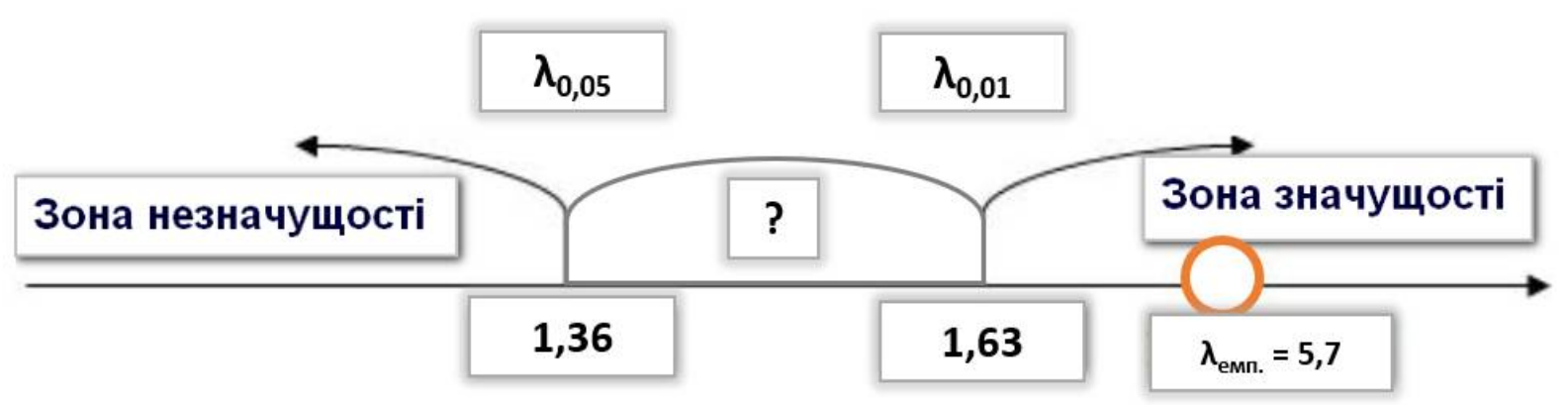

Рис. 4. Графічне розташування емпіричного значення у зоні значущості з урахуванням критичного для співставлення рівня сформованості готовності до професійної діяльності в умовах 


\section{інформаційно-освітнього середовища за дослідницько-творчим критерієм до формувального етапу по завершенню формувального експерименту}

Висновки. В ході дослідження готовності бакалаврів 3 агроінженерії до професійної діяльності в умовах інфрормаційноосвітнього середовища було виконано експериментальну перевірку запропонованої моделі. Було представлено співставлення рівня сфрормованості готовності до профресійної діяльності в умовах інфрормаційно-освітнього середовища за дослідницько-творчим, планово-мотиваційним, конструктивно-операційним та рефрлексивнооцінювальним критерієм до фрормувального етапу по завершенню формувального експерименту. Отримані дані свідчать про те, що рівень готовності бакалаврів з агроінженерії до професійної діяльності в умовах інформаційно-освітнього середовища за всіма критеріями до формувального етапу в експериментальній групі не вищий, ніж у контрольній.

\section{תimepamypa:}

1. Havrish, V., Batsurovska, I., Dotsenko, N., \& Kalinichenko, A. (2019). The implementation of massive open online courses for training future engineers in higher education. Trends in education, (p. 57). Olomouc, Czech Republic.

2. Bobrova, L., \& Marinova, O. (2013). Information Educational Environment-The Basis for Work with Remote Audience. World Applied Sciences Journal 27 (Education, Law, Economics, Language and Communication), 515-518.

3. Денисенко, С. М. (2017). Мультимедійна лекція як компонент освітнього середовища ВН3 (на прикладі підготовки фахівців видавництва та поліграфрії). Інфрормаційні технології в освіті. № 2 (31), 46-54. doi:10.14308/ite000632 
4. Биков, В. Ю. (2005). Відкрите навчальне середовище та сучасні мережні інструменти систем відкритої освіти. Науковий часопис Національного педагогічного університету імені М. П. Драгоманова. Серія 2.(9 (16)), С. 3-9.

5. Смирнов, Н. В. (1944). Приближение законов распределения случайных величин по эмпирическим данным. УМН, 1944, № 10, 179-206

\section{References:}

1. Havrish, V., Batsurovska, I., Dotsenko, N., \& Kalinichenko, A. (2019). The implementation of massive open online courses for training future engineers in higher education. Trends in education, ( $p$. 57). Olomouc, Czech Republic.

2. Bobrova, L., \& Marinova, O. (2013). Information Educational Environment-The Basis for Work with Remote Audience. World Applied Sciences Journal 27 (Education, Law, Economics, Language and Communication), 515-518.

3. Denisenko, S. M. (2017). Multimediyna lektsiya yak komponent osvitnogo seredovischa VNZ (na prikladi pidgotovki fahivtsiv vidavnitstva ta poligrafiyi). Informatsiyni tehnologiyi $v$ osviti. [Multimedia lecture as a component of the educational environment of universities (on the example of training of publishing and printing specialists). Information technology in education]. 2 (31), 46-54. doi:10.14308/ite000632

4. Bikov, V. Yu. (2005). Vidkrite navchalne seredovische ta suchasni merezhni instrumenti sistem vidkritoyi osviti. Naukoviy chasopis Natsionalnogo pedagogichnogo universitetu imeni $M . P$. Dragomanova. [Open learning environment and modern open-source networking tools. Scientific journal of MP Dragomanov National Pedagogical University]. Seriya 2. (9 (16)), 3-9. 
5. Smirnov, N.V. (1944). Priblizhenie zakonov raspredeleniya sluchaynyih velichin po empiricheskim dannyim. Uspehi matematicheskih nauk. [Approximation of laws of distribution of random variables on empirical data]. Vyp. H. 179-206. 